\title{
Treatment of infantile hemangioma with propranolol: A review of 25 cases
}

\author{
Mohamed Ramadan(a), MD; Karam A Allam(b), MD; Mostafa Hariedy(b), MSc; \\ Ahmed Elsherbiny(b), MD
}

(a) Pediatric Surgery Unit, Sohag Craniofacial Unit, Sohag University Hospital.

(b) Plastic Surgery Department, Sohag Craniofacial Unit, Sohag University Hospital.

Introduction: Hemangioma is considered the most common tumor of infancy. Rapid growth of hemangioma during its proliferative phase can lead to disfigurement and is sometimes associated with complications. Propranolol has been used recently in the treatment for infantile hemangiomas and has shown promising results. We are reporting our initial experience with the use of propranolol in treatment of hemangiomas during infancy.

Patients and methods: This study is a retrospective analysis of data of 25 patients with cutaneous infantile hemangiomas treated with oral propranolol in the hamangioma and vascular malformation clinic, Sohag Craniofacial Unit, Sohag University Hospital.

Results: Favorable response to propranolol was observed in all patients in terms of arrest of growth, reduction of size and/or fading of color of the lesion. No significant side effects were observed necessitating stopping of treatment.

Conclusion: Propranolol is an effective treatment for infantile hemangioma and should be considered as a first line therapy. Also it was safely used in infancy with no significant complications reported in our series.

Key words: Hemangioma, propranolol, medical treatment, systemic treatment, treatment outcome.

\section{Introduction:}

Hemangiomas are considered the most common tumors of infancy with an occurrence rate of approximately 1 in 10 children. ${ }^{1}$ Hemangiomas represent an aesthetic deformity for the patients and sometimes functional problems. Specific for haemangiomas, it starts with the phase of proliferation, then a stationary phase and finally the involution phase which partially regresses over several years. The proliferative growth may be complicated by ulceration, bleeding, or infection with some lesions manifested by potentially dangerous symptoms. ${ }^{1}$

Current treatment approaches for infantile hemangiomas include topical, intralesional, and systemic therapies. ${ }^{2}$ Laser and surgical modalities are sometimes used depending on the clinical scenario. Risks and benefits of medical or surgical versus observation alone treatment must be carefully weighed in tailoring management to the specific clinical situation at hand. ${ }^{2}$ There are many treatment lines described for hemangiomas which include Intralesional and systemic corticosteroids, ${ }^{3}$ chemotherapy (vincristine and interferon alpha) ${ }^{4}$, liquid nitrogen cryotherapy, ${ }^{5}$ laser ablation ${ }^{6}$ and surgical excision. ${ }^{7}$ Timing of treatment and method of administration depend on the clinical situations. Other factors that affect therapeutic choices include; age of the patient, location, and size of the hemangioma and the anticipated complications. ${ }^{2}$

Propranolol, a non-selective beta-blocker 
with membrane stabilizing activity, causing accelerated involution of hemangioma, was first reported in 2008 by Leìauteì-Labrel̀ze following an incidental finding. ${ }^{8}$ This finding has been supported by later additional reports. ${ }^{9-12}$ This retrospective study reports our initial experience with the use of proplanolol in the treatment of hemagiomas. The objective of this study is to describe and analyze our protocol of using propranolol as a first-line treatment and a single therapy in the management of infantile hemangioma.

\section{Patients and methods:}

A retrospective review of 25 patients having cutaneous infantile hemangioma were treated with oral propranolol. The study was performed in the hemangioma and vascular malformation clinic of Sohag Craniofacial Unit at Sohag University Hospital from October 2009 to February 2012.

Reviewed data included sex, location of the lesion, photography, age at diagnosis, age at start of treatment, indication of starting treatment, pre-treatment assessment, dose and duration of treatment, favorable response to treatment and any side effects.

25 patients (10 males and 15 females) with their ages at presentation ranged from 2 to14 months with an average 5.5 months. The lesions were located in the head/face/neck (18 hemangiomas; 62\%), trunk (6 hemangiomas; $21 \%$ ) and upper/lower extremity (5 hemangiomas; $17 \%$ ). The lesions were found in multiple locations in four cases (16\%). There was associated invasion of the trachea (confirmed by a bronchoscope) in two cases with cheek and neck hemangioma Table (1).

Before starting treatment with propranolol, all patients were assessed by a pediatrician for baseline evaluation which included medical history, clinical chest and cardiac assessment and ECG. Treatment with propranolol was initiated at presentation for all patients after informing the parents about the drug and its possible side effects and getting signed informed consents. Oral propranolol was given to all patients in a dose of $3 \mathrm{mg} / \mathrm{kg}$ /day divided in 3 doses. The dose was gradually increased starting by $1 \mathrm{mg} / \mathrm{kg} /$ day for a week, doubled in the second week to reach $3 \mathrm{mg} /$ $\mathrm{kg} /$ day in the third week. Follow up during treatment was weekly in the first 3 weeks then twice weekly for evaluation of compliance to treatment and dosing, assessing response to treatment and observing any side effects.

All of the following were considered favorable response to treatment with propranolol: arrest of growth of the lesion over the period of treatment during the early active proliferation phase, reduction of size of the lesion, healing of any ulcers over the lesion, lightening of the color of the lesion from red to grey/white, or flattening of the surface of the lesion.

Because of the retrospective nature of the study, no volumetric measurement of the lesion before or after treatment was available.

Inclusion criteria comprised the rapidly growing haemangioma, lesion with functional or significant cosmetic deformity, lesion likely to affect physiological functions or cause significant cosmetic deformity, even in smaller lesions with high cosmetic concern and parents' wishes.

\section{Results:}

The duration of treatment ranged from 1.5 to 4.5 months with an average of 2.6 months. The duration of follow up ranged from 3.5 to 9.5 months with an average of 6.5 months. A favorable response to treatment was seen in all patients in terms of arrest of growth of the lesion, decrease in size and fading of the color of the lesion. Two cases were presented with ulcers which were healed with treatment. One case with cheek and neck hemangioma associated invasion of the trachea (confirmed by a bronchoscope) was complaining of stridor which improved after 4.5 months of treatment.

No side effects were reported by the family or observed by the authors during or after treatment. The authors did not report regrowth during the period of follow up. Case examples are shown in Figures $(\mathbf{1 , 2 , 3 )}$.

\section{Discussion:}

Until recent time, corticosteroid was considered the first-line treatment for 

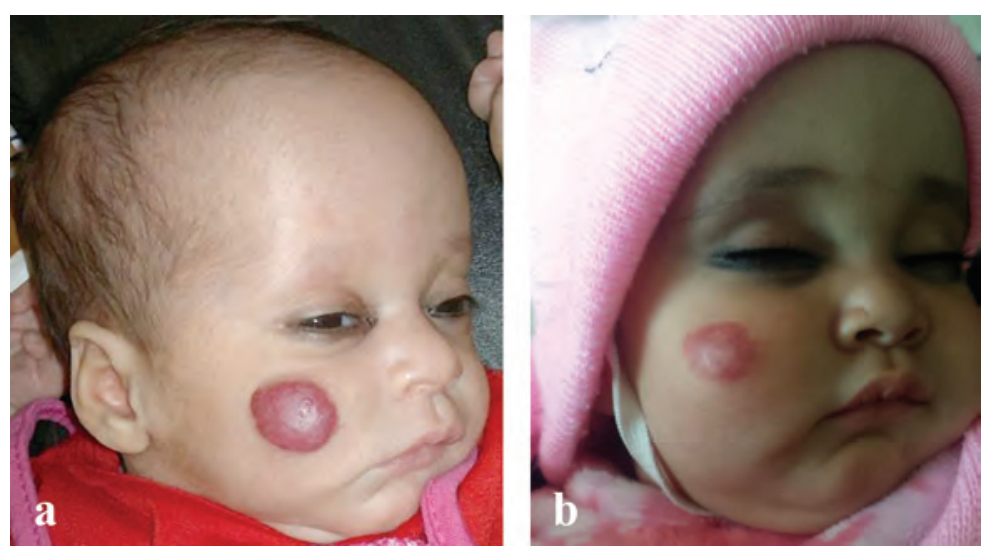

Figure (1): Hemangioma of the right cheek at the age of 3 months (A) and at the age of 7 months after 4 months of treatment with propranolol (B).
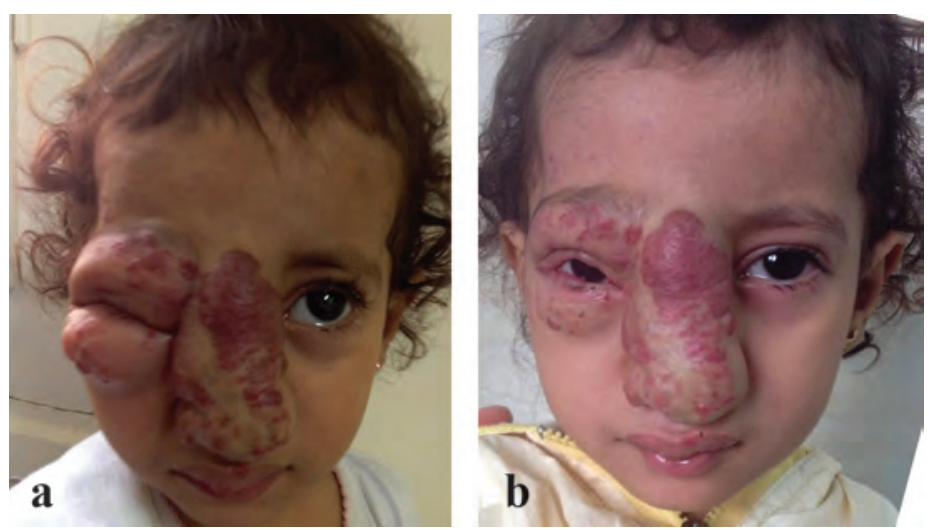

Figure (2): Hemangioma affecting the whole nose and right periorbital region at the age of 12 months $(A)$ and at the age of 15 months after 3.5 months of treatment with propranolol $(B)$.
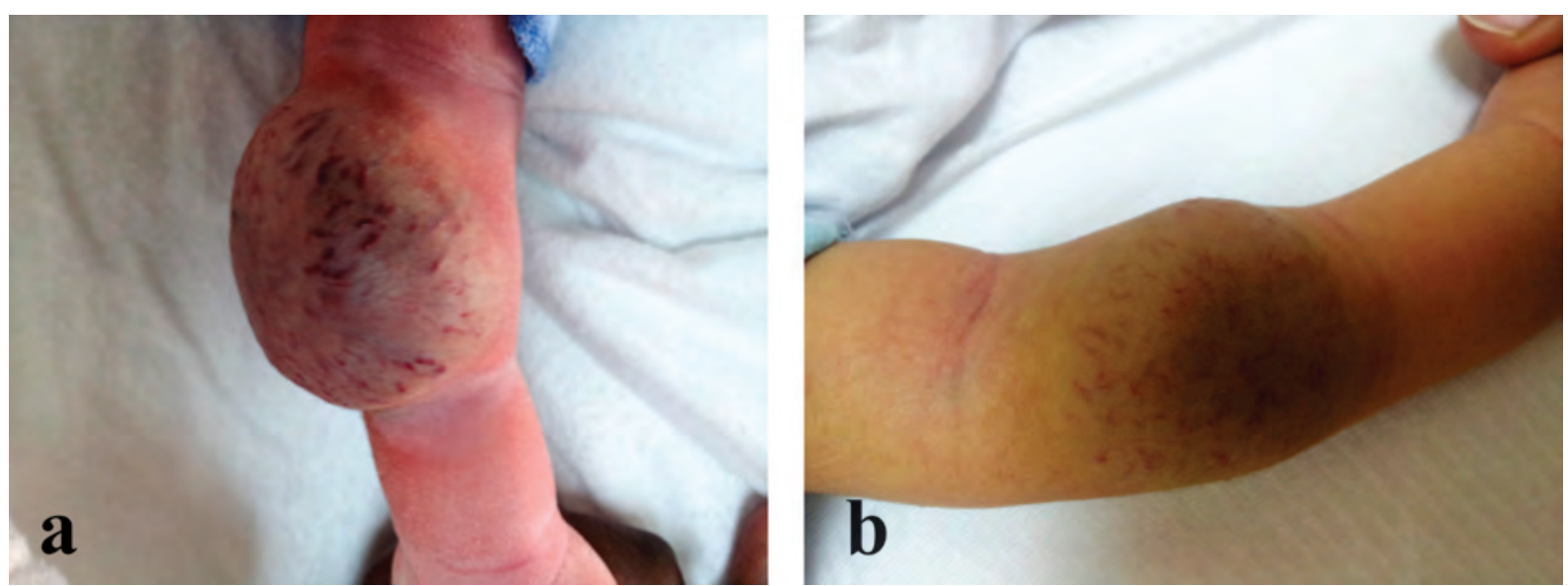

Figure (3): Hemangioma of the left forearm at the age of 3 months (A) and at the age of 7 months after 4 months of treatment with propranolol (B). 
Table 1: The presentation of the patients.

\begin{tabular}{|l|l|l|l|}
\hline $\begin{array}{c}\text { Age } \\
\text { (M) }\end{array}$ & Sex & & \multicolumn{1}{c|}{$\begin{array}{c}\text { Treatment duration } \\
\text { (Months) }\end{array}$} \\
\hline 4 & F & Cheek. & 3 \\
3 & F & Cheek (figure 1). & 4 \\
14 & M & Cheek. & 2 \\
3 & M & Cheek, neck. & 3 \\
4 & F & Cheek, neck. & 4.5 \\
3 & M & Nose. & 1.5 \\
4 & F & Nose. & 1.5 \\
3 & M & Nose. & 2 \\
2 & M & Nose. & 4.5 \\
5 & F & Nose. & 2 \\
12 & F & Nose, periorbital (figure 2). & 3.5 \\
4 & F & Upper lip. & 3.5 \\
6 & M & Upper lip. & 3 \\
2 & F & Lower lip. & 2.5 \\
9 & M & Forehead. & 3 \\
6 & F & Back. & 2 \\
10 & F & Back. & 2 \\
5 & M & Back. & 2 \\
11 & M & Chest. & 1.5 \\
4 & F & Loin. & 2 \\
3 & F & Back- Thigh. & 1.5 \\
7 & F & Arm. & 2.5 \\
3 & F & Forearm. & 3 \\
3 & M & Forearm (figure 3). & 4 \\
9 & F & Leg. & 2 \\
\hline & & & \\
\hline
\end{tabular}

infantile hemangioma in the proliferative phase included systemic or intralesional administration. ${ }^{8}$ In turn, localized or residual infantile hemangioma in the involutive phase were treated with surgical excision or laser therapy. ${ }^{13,14}$

Steroids have a long record of targeting the proliferative phase of hemangiomas causing their shrinkage; however, they can cause significant side effects and rebound growth can occur upon cessation of treatment. ${ }^{15}$ Likewise, chemotherapeutic options, such as vincristine or interferon, can have significant side effects, and also require port placement. ${ }^{15}$ A meta-analysis study conducted by Izadpanah et al ${ }^{16}$ revealed that propranolol achieves a greater response rate in the treatment of infantile hemangiomas in comparison with corticosteroids with response rate approaching $100 \%$ compared to less than $90 \%$ for corticosteroids. ${ }^{16}$

Propranolol is a non-selective $\beta$-blocker developed in the 1950s by Sir James Black ${ }^{17}$ and the first found to be useful in clinical medicine. ${ }^{17}$ Propranolol use for infantile hemangiomas was accidentally discovered in 2008 by a group of physicians from Bordeaux Children's Hospital in France in several patients with extensive infantile hemangiomas who received treatment with propranolol for cardiac problems. ${ }^{8}$ Promising results with regression of hemangioma followed the initiation of propranolol without recurrence of hemangioma growth were reported. ${ }^{48}$

The mechanism of action of propranolol on hemangioma is still unclear. It is hypothesized that as a $\beta$-adrenergic antagonist it induces vasoconstriction, resulting in colour change and palpable softening of the hemangioma $^{8}$, or that propranolol might 
cause downregulation of growth factors, such as vascular endothelial growth factor, and upregulation of cellular apoptosis. ${ }^{8,17}$

Hemangioma-derived stem cells (HemSCs) are considered the cellular precursors of infantile hemangioma. ${ }^{18}$ These cells have been used to develop a murine hemangioma model. It was found that propranolol inhibited angiogenesis via down-regulating the expression of vascular endothelial growth factor in hemangioma derived stem cells. ${ }^{18,19}$ Also propranolol was shown to have effect on primary infantile hemangioma endothelial cells (IHECs) by causing significant apoptosis through the extrinsic and intrinsic pathways. There was marked increase in the expression of caspase-8, cytochrome c, apoptosisinducing factor, caspase-3 and poly (ADPribose) polymerase 1 , as well as a concomitant reduction in lamin B1 expression in a dose dependant manner. ${ }^{20}$

There was a concern about which stage of hemangioma could propranolol to be given for better response. In a study with two groups of patients, 37 out of 38 patients showed response to propranolol who started treatment before reaching the age of one year (97\%), whereas the proportion was 23 out of 31 patients who started treatment after reaching one year of age (74\%). ${ }^{21}$ Our patient population was all in the proliferative stage or near its end. The previous study could suggest that propranolol could be a valuable medical treatment for cases presented late after the end of the proliferative stage.

Studies showed marked success in using propranolol for treating infantile hemangiomas with a response rate reaching $100 \%$ in most studies with the range from fair to excellent results. ${ }^{9-12,22-26}$ Our study showed response in all cases ranged from arrest of growth of the lesion, decrease in size, fading of the color of the lesion and healing of ulcers. No considerable side effects were reported by the family or observed by the authors during or after treatment.

Although propranolol is considered a safe drug, its adverse effects are in the form of bradycardia, hypotension, hypoglycemia, and bronchospasm. ${ }^{27,28}$ Electrocardiograms and echocardiograms were recommended by some authors for all patients before the initiating propranolol treatment to rule out contraindications to $\beta$-blockade. ${ }^{27,28}$ Slowly increasing the dose of the drug and close monitoring of heart rate, blood pressure, and serum glucose levels have also been recommended in the initial phase of treatment. ${ }^{27,28}$

Albuquerque et $\mathrm{al}^{21}$ reported their results with 69 patients with hemangiomas treated with propranolol. They reported no cases needed to discontinue propranolol due to serious or intolerable side effects. They found that 16 patients reported mild side effects in the form of transitory dyspnea, cold extremities, precordial pain or slow weight gain. Taking into consideration that the patient population in the previous study was up to 19 years old and they used doses up to $4 \mathrm{mg} / \mathrm{Kg}^{21}$

Georgountzou et al ${ }^{26}$ admitted their patients for 24 hours for heart rate and blood pressure monitoring every hour for $6 \mathrm{~h}$ following each dose (twice daily) and blood glucose testing $1 \mathrm{~h}$ after each dose. They also recorded the heart rate and blood pressure after one week then monthly. No hypoglycemia reported but slight hemodynamic changes occurred in 4 patients without hindrance of initiating or stopping the treatment. ${ }^{26}$

Propranolol is a cheap, effective and safe treatment of hemangioma during infancy. It should be considered the first line treatment of hemangioma due to the better response rate and fewer side effects reported than corticosteroids. Additional study on a larger scale of patients with the use of objective volume assessments (e.g 3D camera) is advised. Also longer follow up is needed to assess the relapse rate.

\section{Reference}

1- Zimmermann AP, Wiegand S, Werner JA, Eivazi B: Propranolol therapy for infantile haemangiomas: Review of the literature. International Journal of Otorhinolaryngology 2010; 74: 338-342.

2- Maguiness SM and Frieden IJ: Current management of infantile hemangiomas. Semin Cutan Med Surg 2010; 29(2): 106-14.

3- Bennett ML, Fleischer AB Jr, Chamlin 
SL, Frieden IJ: Oral corticosteroid use is effective for cutaneous hemangiomas: An evidence-based evaluation. Arch Dermatol 2001; 137(9): 1208-1213.

4- Ricketts RR, Hatley RM, Corden BJ, Sabio H, Howell CG: Interferon-alpha-2a for the treatment of complex hemangiomas of infancy and childhood. Ann Surg 1994; 219(6): 605-612.

5- Chen WL, Zhang B, Li JS, Yang ZH, Wang YJ, Huang ZQ, et al: Liquid nitrogen cryotherapy of lip mucosa hemangiomas under inhalation general anesthesia with sevoflurane in early infancy. Ann Plast Surg 2009; 62(2): 154-157.

6- Bruscino N, Bonan P, Cannarozzo G, Moretti S, Lotti T, Campolmi P: Laser use in infantile hemangiomas, when and how. Dermatol Ther 2012; 25(4): 314-321.

7- Daramola OO, Chun RH, Nash JJ, Drolet BA, North PE, Jensen JN, et al: Surgical treatment of infantile hemangioma in a multidisciplinary vascular anomalies clinic. Int J Pediat Otorhinolaryngol 2011; 75(10): 1271-1274.

8- Leaute-Labreze C, de la Roque DE, Hubiche T, Boralevi F, Thambo JB, Taieb A: Propranolol for severe hemangiomas of infancy. N Engl J Med 2008; 358: 2649-2651.

9- Buckmiller L, Dyamenahalli U, Richter GT: Propranolol for airway hemangiomas: Case report of novel treatment. Laryngoscope 2009; 119: 2051-2054.

10- Denoyelle F, Leboulanger N, Enjolras O, Harris R, Roger G, Garabedian EN: Role of Propranolol in the therapeutic strategy of infantile laryngotracheal hemangioma. Int J Pediatr Otorhinolaryngol 2009; 73: 1168-1172.

11- Siegfried EC, Keenan WJ, Al-Jureidini S: More on propranolol for hemangiomas of infancy. NEngl J Med 2008; 359: 2846-2847.

12- Theletsane T, Redfern A, Raynham O, Harris T, Prose NS, humalo NP: Life-threatening infantile haemangioma: A dramatic response to propranolol. J Eur Acad Dermatol Venereol 2009; 23(12): 1465-1466.

13- Williams $\mathrm{EF}^{3^{\text {rd }}}$, Stanislaw $\mathrm{P}$, Dupree $\mathrm{M}$, Mourtzikos K, Mihm M, Shannon L: Hemangiomas in infants and children. An algorithm for intervention. Arch Facial Plast Surg 2000; 2: 103-111.

14- Hynes S, Narasimhan K, Courtemanche DJ, Arneja JS: Complicated infantile hemangioma of the lip: Outcomes of early versus late resection. Plast Reconstr Surg 2013; 13(3): 373-379.

15- Starkey E and Shahidullah H: Propranolol for infantile haemangiomas: a review. Arch Dis Child 2011; 96(9): 890-893.

16- Izadpanah A, Izadpanah A, Kanevsky J, Belzile E and Schwarz K: Propranolol versus corticosteroids in the treatment of infantile hemangioma: a systematic review and metaanalysis. Plast Reconstr Surg 2013; 131: 601-613.

17- Zimmermann AP, Wiegand S, Werner JA, Eivazi B: Propranolol therapy of infantile haemangiomas: review of the literature. Int J Pediatr Otorhinolaryngol 2010; 74(4): 338-342.

18- Khan ZA, Boscolo E, Picard A, Psutka S, Melero-Martin JM, Bartch TC, et al: Multipotential stem cells recapitulate human infantile hemangioma in immunodeficient mice. J Clin Invest 2008; 118: 2592-2599.

19- Zhang L, Hua-Ming Ma, Zheng J, Zheng JW, Wang YA, Qin ZP, et al: Propranolol inhibits angiogenesis via down-regulating the expression of vascular endothelial growth factor in hemangioma derived stem cell. Int $J$ Clin Exp Pathol 2014; 7(1): 48-55.

20- Tu JB, Ma RZ, Dong Q, Jiang F, Hu XY, Li $\mathrm{QY}$, et al: Induction of apoptosis in infantile hemangioma endothelial cells by propranolol. Exp Ther Med 2013; 6(2): 574-578.

21- Albuquerque JC, Magalhães RA, Félix JA, Bastos MV, Fontenele JB, Trompieri NM, et al: Treatment of children and adolescents with hemangioma using propranolol: Preliminary results from a retrospective study. Sao Paulo Med J 2014; 132(1): 48-54.

22- Manunza F, Syed S, Laguda B, Linward J, Kennedy H, Gholam K, et al: Propranolol for complicated infantile haemangiomas: A case series of 30 infants. Br J Dermatol 2010; 163(2): 466-468.

23- Laforgia N, MilanoA, De Leo E. Hemangioma and propranolol: Some remarks at the end of treatment. Differences from corticosteroids. Eur J Pediat Dermatol 2009; 19:175-191.

24- Qin ZP, Liu XJ, Li KL, Zhou Q, Yang XJ, Zheng JW: Treatment of infantile hemangiomas with low-dose propranolol: Evaluation of short-term efficacy and safety. Zhonghua Yi Xue Za Zhi 2009; 89(4): 3130-3134.

25- Holmes WJ, Mishra A, Gorst C, Liew SH: Propranolol as first-line treatment for rapidly proliferating infantile haemangiomas. J Plast 
Reconstr Aesthet Surg 2011; 64(4): 445-451. 26- Georgountzou A, Karavitakis E, Klimentopoulou A: Propranolol treatment for severe infantile hemangiomas: A singlecentre 3-year experience. Acta Pcediatrica 2012; 101: 469-474.

27- Sans V, de la Roque DE, Berge J, Grenier $\mathrm{N}$, Boralevi F, Mazereeuw-Hautier J, et al: Propranolol for severe infantile hemangiomas: Follow-up report. Pediatrics 2009; 124(3): 423-431.

28- Lawley LP, Siegfried E, Todd JL: Propranolol treatment for hemangioma of infancy: Risks and recommendations. Pediatr Dermatol 2009; 26(5): 610-614. 